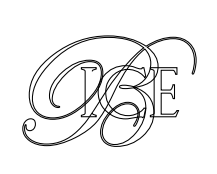

\title{
EL RETAIL EN ESPAÑA, CADA VEZ MENOS INTERIOR, CADA VEZ MÁS DIGITAL
}

\begin{abstract}
"Coexisten en España dos sistemas de distribución complementarios entre sí: el primero constituido por empresas y tecnologías modernas, $y$ el segundo integrado por las formas tradicionales de comercio que siguen prestando importantes servicios a la sociedad española y juegan un papel trascendental en la estabilidad de la población activa, pero que deben emprender una actualización y tecnificación que les permita afrontar el marco de la libre competencia».
\end{abstract}

Exposición de Motivos de la Ley de Ordenación del Comercio Minorista.

En este artículo se analiza el sector de distribución comercial minorista en España, en el que la penetración del segmento online se halla en sus inicios, aunque la progresión es acelerada. Más allá de los datos macroeconómicos se dibuja una actividad con potencial de transformación de la economía y la sociedad. La velocidad de incorporación del cambio tecnológico por parte de las empresas es determinante para, en primera instancia, sobrevivir en el mercado digital; y en definitiva alcanzar la excelencia que permita competir en el largo plazo con los grandes operadores globales. Corresponde a los poderes públicos diseñar el marco de acompañamiento y facilitación que contribuya a la competitividad del sector, al tiempo que se preservan y garantizan los objetivos legítimos de política general.

Palabras clave: comercio electrónico, comercio minorista, pyme, competitividad.

Clasificación JEL: E21, L81.

\section{El sector de comercio minorista en España}

Oímos hablar a menudo de cambio de época, de cuarta revolución industrial, de transformaciones 4.0, de conectividad, de digitalización... Se

\footnotetext{
* Este artículo ha sido elaborado por Cristina Teijelo Casanova. Técnico Comercial y Economista del Estado. Subdirectora General de Comercio Internacional de Servicios y Comercio Digital.

Versión de julio de 2019.

DOI: https:/doi.org/10.32796/bice.2019.3114.6893
}

trata de fenómenos que se están produciendo a una escala y una velocidad desconocidas hasta ahora. Es lo que se ha dado en llamar disrupción, una dinámica que actúa como palanca para el cambio: lo disruptivo nos fuerza a transformarnos. Más allá de la mera supervivencia, los operadores se ven forzados a buscar la excelencia para la competitividad.

El sector de la distribución comercial es, por su propia naturaleza, protagonista de la digitalización. La comercialización de productos y $\triangleright$ 


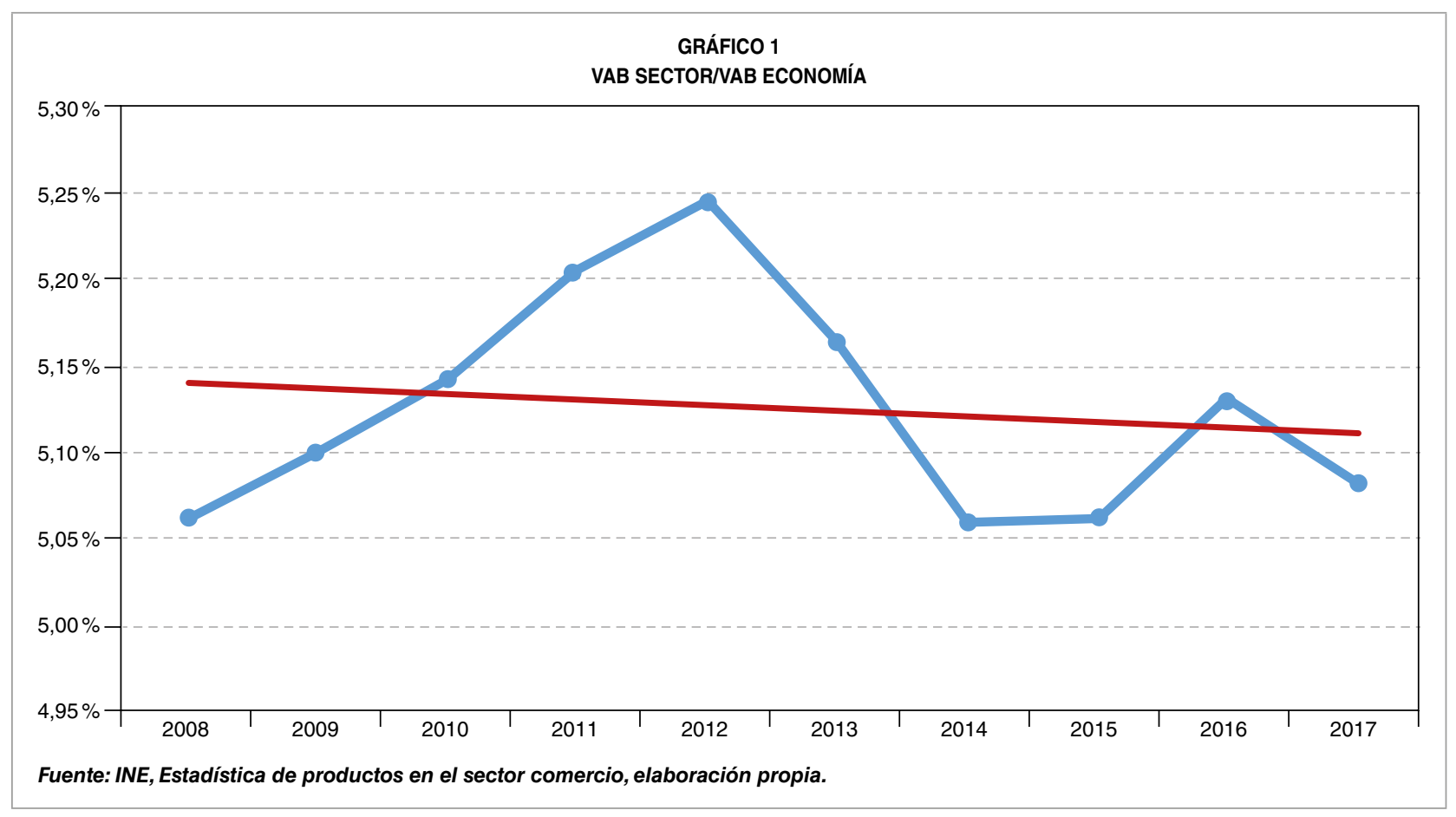

servicios por vía electrónica experimenta un auge sin precedentes. Esto genera un nuevo escenario que los comerciantes han de interiorizar buscando estrategias para competir con éxito en un mundo en continuo cambio. A pesar de que la adaptación a las necesidades del cliente está en el ADN del comerciante, este se enfrenta en la actualidad a un reto mayor.

Se trata de un sector en permanente evolución. No obstante, el cliente sigue buscando el trato personalizado y profesional que le ayude en su decisión de compra. Esto determina que no podamos hablar de una dicotomía entre lo online y lo offline, sino más bien de un solapamiento de modelos de venta que buscan sofisticar la experiencia del usuario en función de las necesidades de la demanda en un contexto omnicanal: el consumidor, que identifica la innovación con la tecnología, espera una experiencia de compra más digital también en los establecimientos comerciales físicos.
El sector está adaptándose gradualmente a este nuevo escenario mediante inversiones en capital humano y tecnología. Se enfrenta, sin embargo, a una capacidad limitada de acometer inversiones, en gran parte relacionada con el reducido tamaño de las empresas que lo componen.

\section{Datos macroeconómicos}

El comercio minorista es la actividad de intermediación comercial que sitúa los productos a disposición del consumidor final ${ }^{1}$. Se trata de un sector económico de importancia vital por su carácter conector entre producción y consumo y por su peso económico que contribuye $\triangleright$

1 Si bien el concepto de distribución minorista abarca la venta tanto de productos como de servicios, en este artículo nos vamos a centrar en las actividades englobadas en el capítulo 47 de la Clasificación Nacional de Actividades Económicas (CNAE), «Comercio al por menor, excepto de vehículos de motor y motocicletas». Para una explicación más detallada del contenido del capítulo 47 véase el Anexo 1. 
CUADRO 1

INDICADORES ECONÓMICOS DEL SECTOR

\begin{tabular}{|c|c|c|c|c|c|c|}
\hline Años & $\begin{array}{c}\text { Cifra de } \\
\text { negocios } \\
\text { (millones de } € \text { ) }\end{array}$ & $\begin{array}{c}\text { VAB } \\
\text { (millones de } € \text { ) }\end{array}$ & $\begin{array}{c}\text { Personal } \\
\text { ocupado } \\
\text { (miles) }\end{array}$ & $\begin{array}{l}\text { Empresas } \\
\text { (número) }\end{array}$ & $\begin{array}{c}\text { Establecimientos } \\
\text { (número) }\end{array}$ & $\begin{array}{c}\text { Superficie física } \\
\text { de venta } \\
\left(\mathrm{m}^{2}\right)\end{array}$ \\
\hline 2008 & 240.651 & 51.926 & 2.016 & 526.294 & - & 73.643 .137 \\
\hline 2009 & 219.519 & 51.314 & 1.899 & 516.518 & - & 75.359 .044 \\
\hline 2010 & 221.382 & 50.903 & 1.869 & 505.605 & 617.548 & 73.922 .273 \\
\hline 2011 & 217.287 & 51.202 & 1.897 & 492.999 & 606.131 & 71.839 .557 \\
\hline 2012 & 210.487 & 50.037 & 1.870 & 485.987 & 600.595 & 68.257 .854 \\
\hline 2013 & 204.932 & 48.323 & 1.858 & 477.463 & 592.172 & 67.412 .158 \\
\hline 2014 & 204.260 & 47.790 & 1.875 & 469.817 & 583.908 & 65.863 .023 \\
\hline 2015 & 213.134 & 49.653 & 1.908 & 469.938 & 583.796 & 67.651 .703 \\
\hline 2016 & 223.909 & 52.072 & 1.900 & 462.450 & 576.211 & 71.278 .381 \\
\hline 2017 & 232.002 & 53.741 & 1.912 & 458.169 & 573.676 & 72.446 .817 \\
\hline $\begin{array}{l}\text { Tasa de } \\
\text { variación }\end{array}$ & $-3,59 \%$ & $10,09 \%$ & $-9,44 \%$ & $-12,94 \%$ & $-13,89 \%$ & $-1,62 \%$ \\
\hline
\end{tabular}

CUADRO 2

DIMENSIÓN ECONÓMICA, VARIOS SECTORES, 2017

\begin{tabular}{|c|c|c|c|}
\hline Sectores & VAB/VAB total $\%$ & Ocupados/total ocupados \% & VAB/ocupado (€) \\
\hline Hostelería & 7,16 & 7,16 & 45.793 \\
\hline Comercio minorista & 5,08 & 9,83 & 28.107 \\
\hline Construcción & 6,12 & 6,01 & 56.615 \\
\hline Servicios financieros y seguros & 3,90 & 2,30 & 94.228 \\
\hline Agricultura, ganadería, silvicultura y pesca & 2,96 & 4,31 & 38.180 \\
\hline \multicolumn{3}{|l|}{ Valor medio de la economía española } & 56.154 \\
\hline
\end{tabular}

de forma sostenida en el tiempo con aproximadamente un $5 \%$ a la generación del valor añadido bruto (VAB) de la economía española².

Sirva para poner el sector en dimensión la consideración de sus principales variables económicas y su evolución a lo largo de la última década.

Si comparamos el retail con otros sectores de similar importancia económica medida en términos del VAB, encontramos que:

2 En el presente estudio, dada la heterogeneidad de fuentes y metodologías disponibles, nos vamos a ceñir a los datos del Instituto Nacional de Estadística (INE) con el fin de mantener, en lo posible, la consistencia. Entre sus ventajas destacaremos la existencia de una serie temporal larga que permite la comparabilidad con una perspectiva amplia (10 años), la disponibilidad de una gran gama de variables de análisis relevantes y, sobre todo, la posibilidad de segmentar por capítulos CNAE, lo que nos permite analizar el objeto de nuestro estudio, el capítulo 47.
- Su peso es prácticamente idéntico al del sector de la construcción y ligeramente por debajo del sector de la hostelería.

- Aporta al VAB 1,3 puntos porcentuales más que el conjunto del sector financiero y de seguros.

- Prácticamente dobla el peso del sector primario en su conjunto.

Emplea casi un $10 \%$ de la población ocupada, por encima del resto de sectores de similar importancia económica que hemos tomado como referencia. Esto determina que la productividad media, medida como VAB por empleado, se sitúe por debajo de las demás. En términos agregados, la productividad de la $\triangleright$ 
Subdirección General de Comercio Internacional de Servicios y Comercio Digital

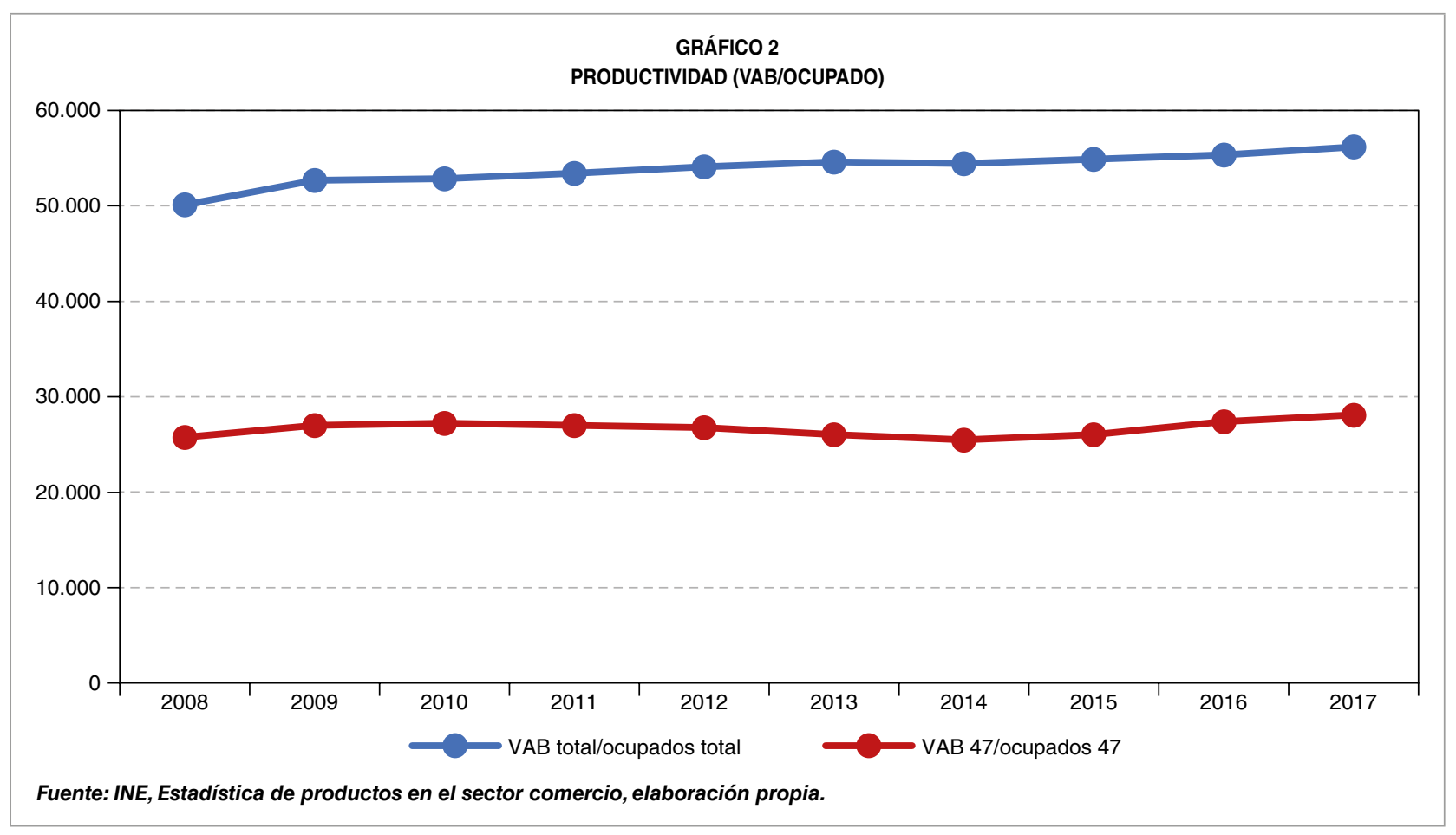

economía española en promedio dobla a la del sector minorista.

Los datos de empleo del sector muestran un alto porcentaje de empleo femenino, en torno a dos tercios del total, ya casi 20 puntos por encima de la media de la economía. El $73,6 \%$ de los afiliados al Régimen General de la Seguridad Social en el sector tienen $\triangleright$

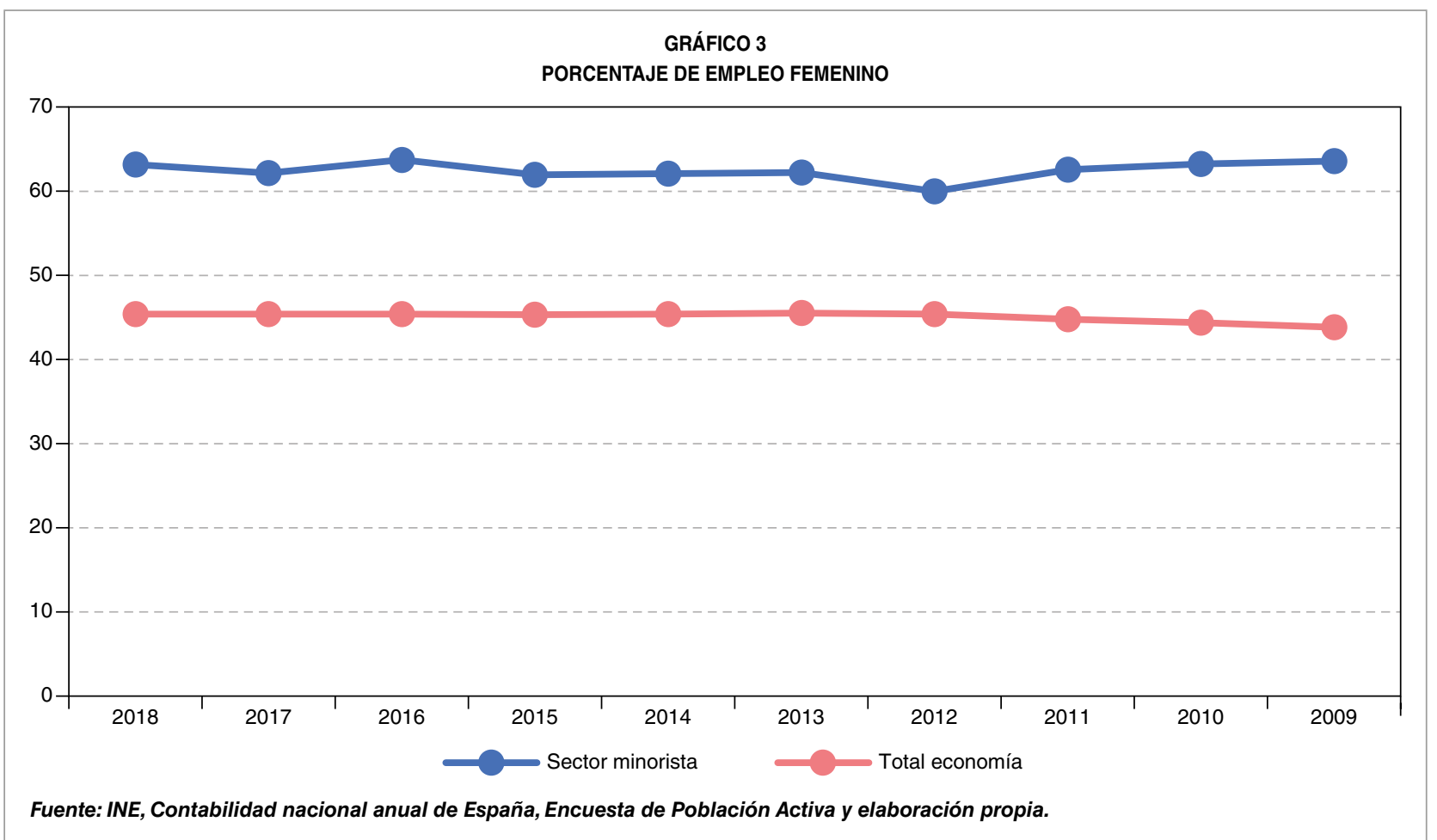




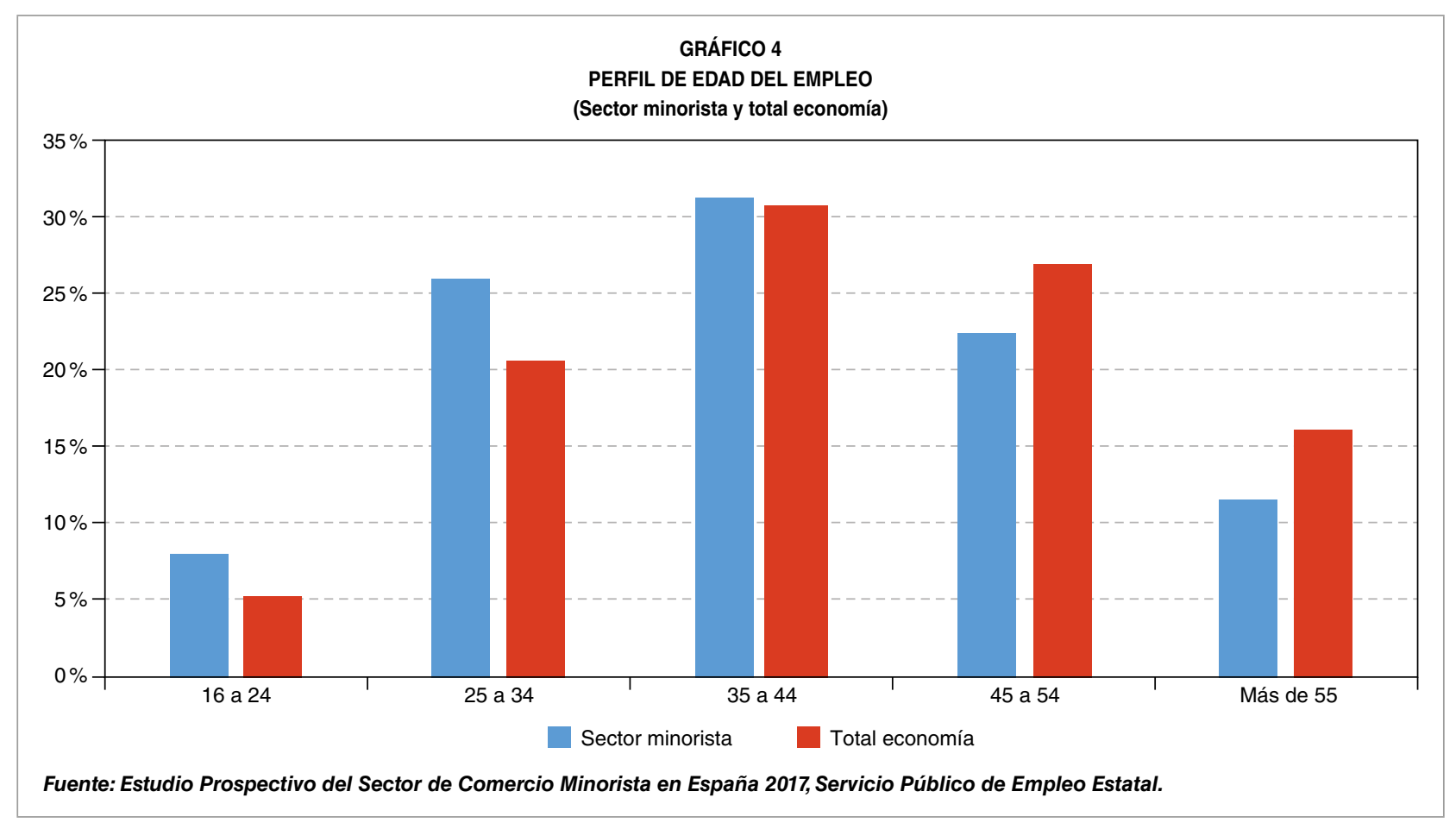

CUADRO 3

NÚMERO DE EMPRESAS MINORISTAS EN ESPAÑA

\begin{tabular}{|l|c|c|c|c|c|}
\hline \multicolumn{1}{|c|}{ Años } & Microempresas & Pequeñas empresas & Medianas empresas & Grandes empresas & Total \\
\hline 2008 & 515.171 & 9.996 & 825 & 302 & 526.294 \\
2009 & 506.257 & 9.147 & 813 & 301 & 516.518 \\
2010 & 497.238 & 7.341 & 740 & 286 & 505.605 \\
2011 & 484.943 & 7.092 & 690 & 274 & 492.999 \\
2012 & 478.460 & 6.567 & 692 & 268 & 485.987 \\
2013 & 470.380 & 6.146 & 670 & 267 & 477.463 \\
2014 & 463.113 & 5.789 & 643 & 272 & 469.817 \\
2015 & 463.190 & 5.836 & 639 & 273 & 469.938 \\
2016 & 455.439 & 6.038 & 697 & 276 & 462.450 \\
2017 & 450.969 & 6.186 & 721 & 293 & 458.169 \\
2018 & 444.400 & 6.054 & 719 & 298 & 451.471 \\
\hline Saldo neto & -70.771 & -3.942 & -106 & -4 & -74.823 \\
\hline Variación & $-13,98$ & $-13,04$ & $-1,33$ & $-14,22$ \\
porcentual & \multicolumn{2}{|l|}{ Fuente: INE, Directorio Central de Empresas y elaboración propia. } \\
\hline
\end{tabular}

contratos indefinidos y el $26,6 \%$ temporales. Por niveles educativos, el $77 \%$ de las contrataciones se realiza con personas que alcanzan al menos el nivel de formación de Enseñanza Secundaria Obligatoria (ESO). Destaca el porcentaje de contrataciones de titulados universitarios, cercano al $10 \%$, del total de las cuales el $76 \%$ corresponde a mujeres. En cuanto a la edad, el perfil del empleo es más joven que el de la economía en su conjunto ${ }^{3}$.

3 Estudio Prospectivo del Sector de Comercio Minorista en España 2017, Servicio Público de Empleo Estatal. 
El sector está formado por más de 450.000 empresas, de las cuales en torno a un $97 \%$ son microempresas (autónomos y empresas con menos de 10 asalariados). La población empresarial del sector a lo largo de los últimos diez años ha experimentado una evolución a la baja, muy en particular en el segmento de la pequeña empresa (de 10 a 49 empleados), cuyo número se reduce un $43 \%$. De forma agregada, el número de empresas del sector cae de forma sostenida a lo largo de la década casi un $13 \%$.

\subsection{Valoración}

Si analizamos la evolución de los principales indicadores del sector a lo largo de la última década ${ }^{4}$, es posible extraer una serie de conclusiones:

- La cifra de negocios cae en términos absolutos entre 2008 y 2017, si bien se detecta una importante tendencia a la recuperación durante los últimos tres años. Este resultado es consistente con la coyuntura macroeconómica de nuestro país durante los años de la crisis.

- La productividad es la mitad que el valor promedio de la economía en su conjunto. Este dato representa una importante vulnerabilidad del sector que lastra su capacidad de crecimiento y de acometer nuevas inversiones.

- Si bien la ocupación cae de forma acumulada a lo largo de la década, el número de empleados promedio por empresa aumenta de 3,83 a 4,17, es decir, la empresa minorista se hace más trabajo-intensiva a lo largo del periodo.
- El número total de empresas, como habíamos visto en el Cuadro 3, disminuye en casi un $13 \%$. Es una tendencia constante a lo largo de toda la serie temporal.

- La facturación media por empresa pasa de 457.255 euros a 506.367 euros, es decir, aumenta un $10 \%$ de forma acumulada a lo largo de la serie temporal.

- El número de establecimientos físicos (locales) promedio por empresa aumenta de 1,22 a 1,25, al igual que sucede con la superficie de venta promedio por empresa, que se incrementa casi un $13 \%$, de 140 a $158 \mathrm{~m}^{2}$.

- Se trata de un sector atendido por mano de obra eminentemente femenina, cualificada y joven.

En estas condiciones, el sector se enfrenta a una etapa de transformación intensa, profunda y acelerada que le debería permitir adaptarse a las nuevas condiciones del mercado. Este proceso de cambio, que se ha dado en llamar «disrupción», ha coincidido en el tiempo con la gran crisis financiera global, dando como resultado la desaparición de los operadores más débiles y menos preparados para hacer frente al nuevo entorno competitivo. La evolución experimentada está configurando un sector más moderno, más intensivo en mano de obra, en locales y en superficie de venta.

Estas conclusiones abundan en las recogidas en el estudio-diagnóstico «La digitalización del Retail en España» 5 , elaborado por la Secretaría de Estado de Comercio en diciembre de 2018.

5 www.comercio.gob.es/es-ES/PDF/DIAGNÓSTICO.V.1.pdf 


\section{La transformación digital del sector}

\subsection{Digitalización de la oferta: las empresas}

El proceso de digitalización de la actividad del comercio minorista tiene dos dimensiones:

- Dimensión interna: se refiere a la introducción de herramientas y tecnologías digitales en la gestión del negocio. Este proceso revierte de forma indudable en una mayor eficiencia, sin embargo el acceso al mismo presenta una serie de barreras de acceso (coste, talento, tiempo...).

- Dimensión externa: se trata de la digitalización de la propia comercialización, es decir, la incorporación del comercio electrónico como medio de venta, lo que incluye el replanteamiento de todas las variables clásicas del marketing: precio, producto, distribución, promoción y logística.

Respecto al ámbito interno de la digitalización, me referiré aquí a la valoración que del estado de digitalización del sector realiza el Observatorio Nacional de las Telecomunicaciones y de la Sociedad de la Información (ONTSI) del Ministerio de Economía y Empresa ${ }^{6}$ y al mencionado diagnóstico «La digitalización del Retail en España».

A pesar de la sensación de que el comercio minorista en nuestro país se encuentra retrasado en el proceso de adopción de tecnologías digitales, los datos indican lo contrario, si bien se detecta una diferencia importante en el grado de penetración de tecnologías, equipos y procesos digitales entre el segmento de pymes

6 «Informe e-Pyme 2017», basado en datos INE. y grandes empresas (por encima de $10 \mathrm{em}$ pleados); y microempresas.

Esta brecha de dimensión se pone de manifiesto en el análisis de parámetros básicos, como la disponibilidad de equipo informático, la conexión a internet o la existencia de página web corporativa. Entre las debilidades del sector destacan el todavía reducido uso de servicios cloud, su escaso uso de herramientas y controles de ciberseguridad y el bajo porcentaje de empleo de especialistas TIC (tecnologías de la información y comunicación). La mayoría de las empresas pertenecientes al sector del comercio minorista (73\%) no dispone de director o responsable técnico de informática, lo que nos lleva a la conclusión de que estas tareas se contratan externamente en la mayor parte de los casos. En materia de software de gestión, más del $70 \%$ de las empresas declara utilizar al menos uno.

De puertas afuera, en el ámbito externo de la digitalización (área comercial), más de la mitad declara disponer de personal con conocimientos digitales y experiencia en comercio online. Sin embargo, tan solo la cuarta parte de las empresas encuestadas participa de forma efectiva en el negocio digital. Respecto al gasto en marketing digital (redes sociales, publicidad dirigida y en menor medida las técnicas basadas en big data), casi un $25 \%$ de los encuestados declaró no dedicar recursos a este concepto, lo que sitúa al sector por debajo de la media nacional. En el otro extremo, un $10 \%$ de las empresas gasta más de la mitad de sus fondos de promoción en el canal online.

Esta valoración de la situación de nuestras empresas minoristas en el proceso de transformación digital debe analizarse en el contexto de nuestros socios de la Unión Europea a través del estudio de los indicadores de la Comisión Europea sobre comercio electrónico. Del $\triangleright$ 


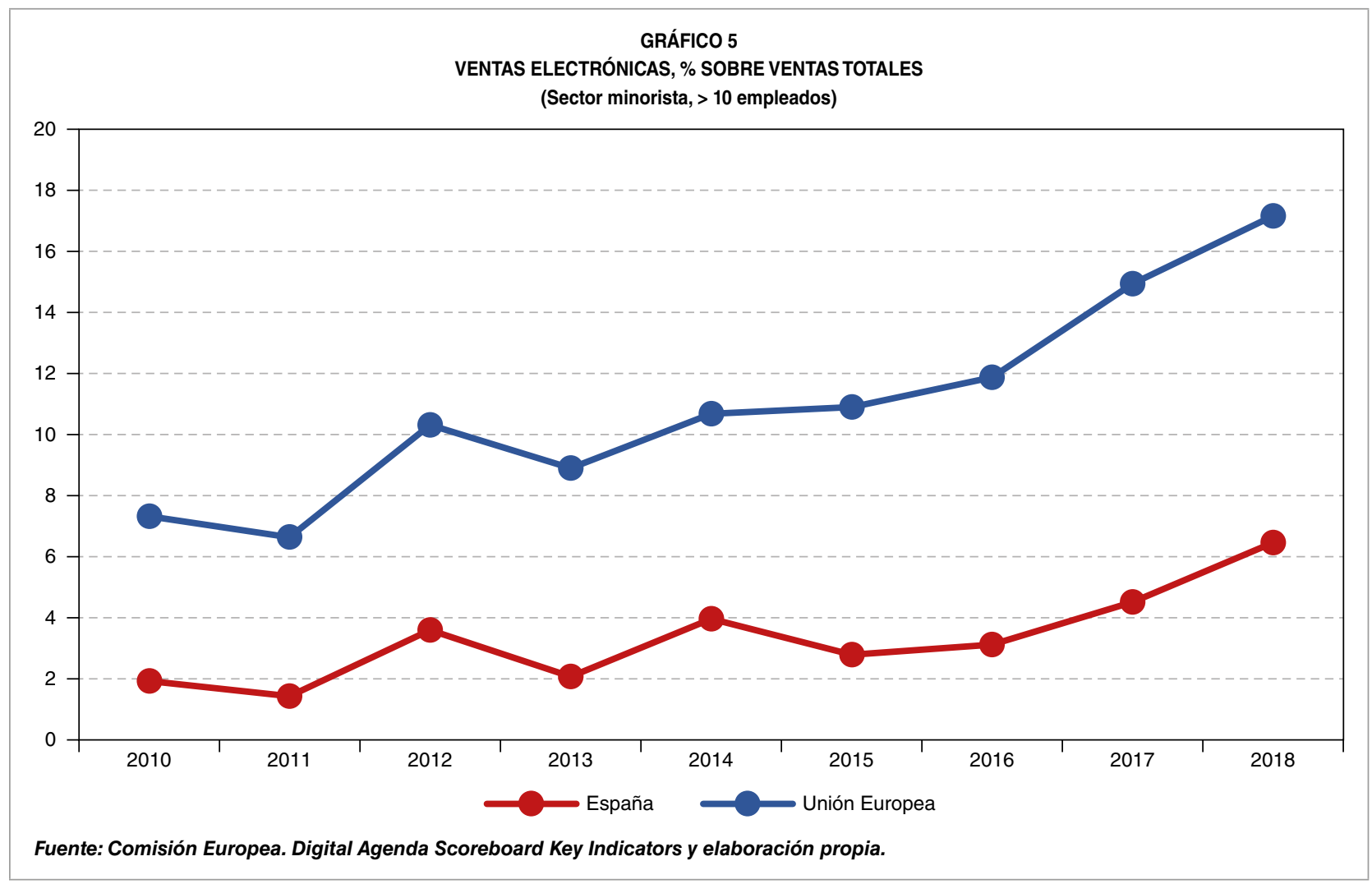

mismo concluiremos que estamos aún lejos de las posiciones de liderazgo, más aún teniendo en cuenta que este portal de datos se refiere solo a empresas con más de 10 empleados. Excluiría, por tanto, las microempresas que, como hemos visto, representan un $97 \%$ del total de nuestro tejido empresarial minorista y cuyo grado de digitalización es sustancialmente inferior. Si lo comparamos con la media UE, concluimos de nuevo que el grado de penetración del comercio digital en nuestro país es aún reducido.

En efecto, en materia de ventas digitales del sector minorista (facturación online respecto a facturación total) existe una brecha entre España y la media europea que aumenta a lo largo de la serie temporal, pasando de 3 a 5 puntos porcentuales?

El «Reglamento sobre el fomento de la equidad y la transparencia para las empresas que utilizan servicios de intermediación en línea» es una propuesta de la Comisión en tramitación que busca reequilibrar derechos y obligaciones entre plataformas online y empresas usuarias.
Recordemos que este dato no se refiere al grado de penetración del comercio electrónico como forma de compra (análisis desde la perspectiva del consumo), sino de la penetración como forma de venta, es decir, hasta qué punto las empresas minoristas españolas se han incorporado al negocio digital.

Si comparamos los datos y la evolución de una serie de Estados miembros representativos, la conclusión anterior se pone de manifiesto de forma aún más acusada: España tiene aún un largo recorrido por delante en la incorporación al comercio online, aunque se constata una progresión positiva.

Desde un ángulo diferente, al ser España el octavo país del mundo en términos de acceso a internet (utilizado por el $85 \%$ de la población), el potencial de desarrollo y crecimiento del comercio online es enorme por el lado de la demanda. Las empresas españolas deben pisar el acelerador digital para absorber en la $\square$ 


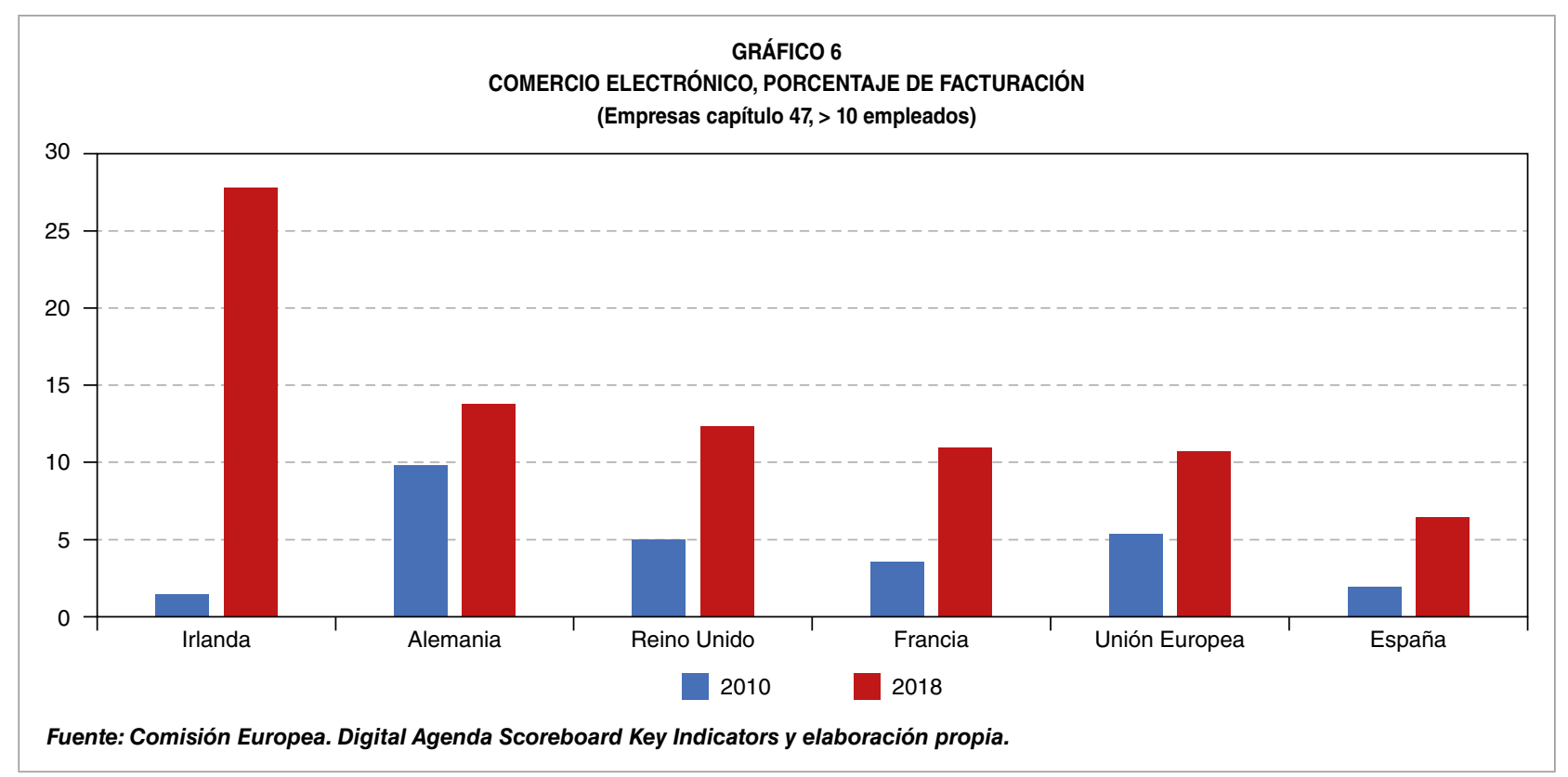

mayor medida posible el negocio que de ello se derivará. Lo vemos a continuación.

\subsection{Digitalización de la demanda: los consumidores}

La incorporación de patrones de consumo digital en los hábitos de compra de los consumidores españoles crece de forma consistente a lo largo de la década, si bien se mantiene aún por debajo de la media europea. La distancia se ha acortado sensiblemente, reduciéndose desde los 14 puntos porcentuales de 2009 hasta los 7 de 2018.

En paralelo al aumento de consumidores online, se está produciendo un incremento progresivo del gasto promedio por consumidor, $\triangleright$

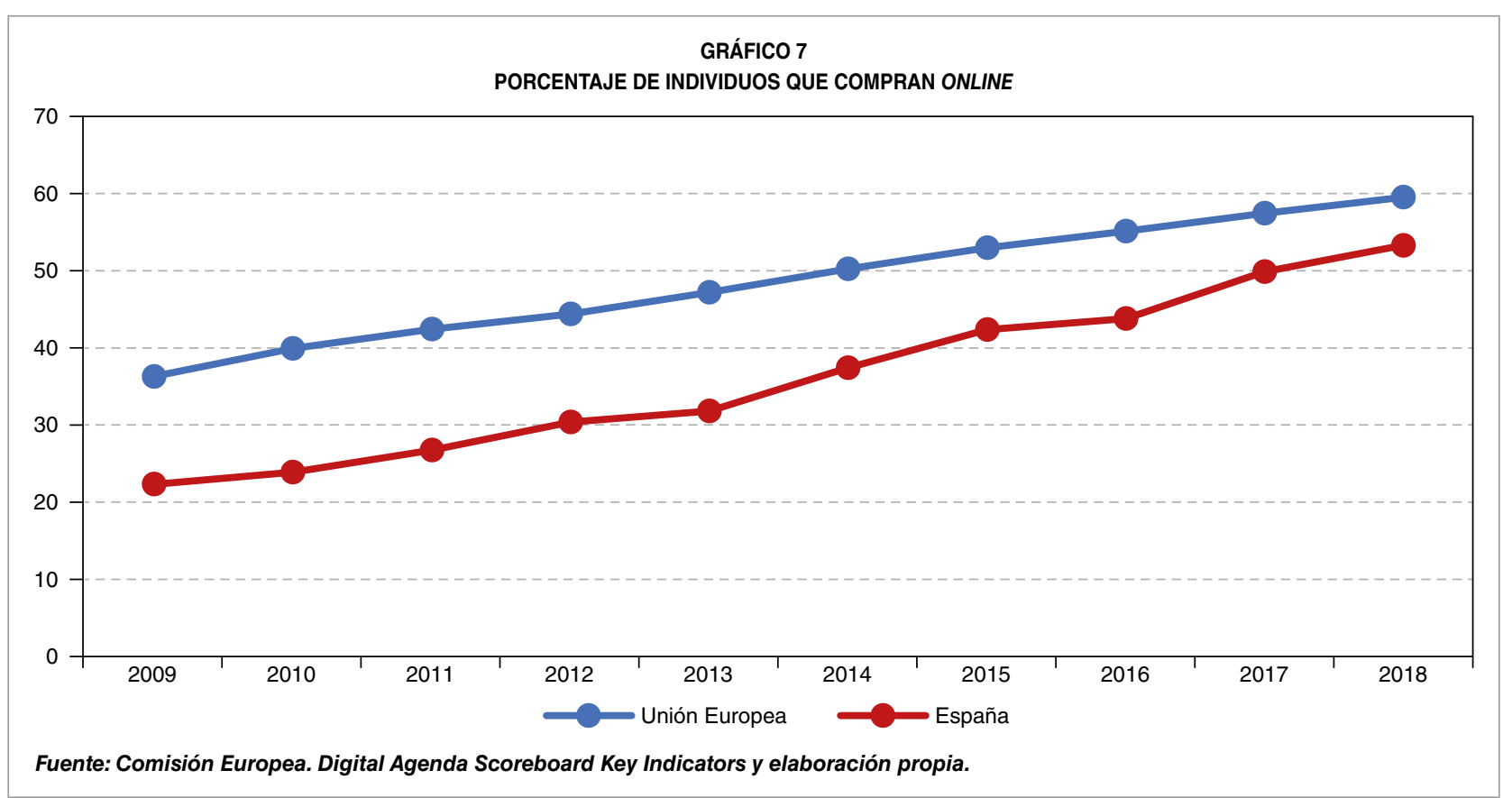




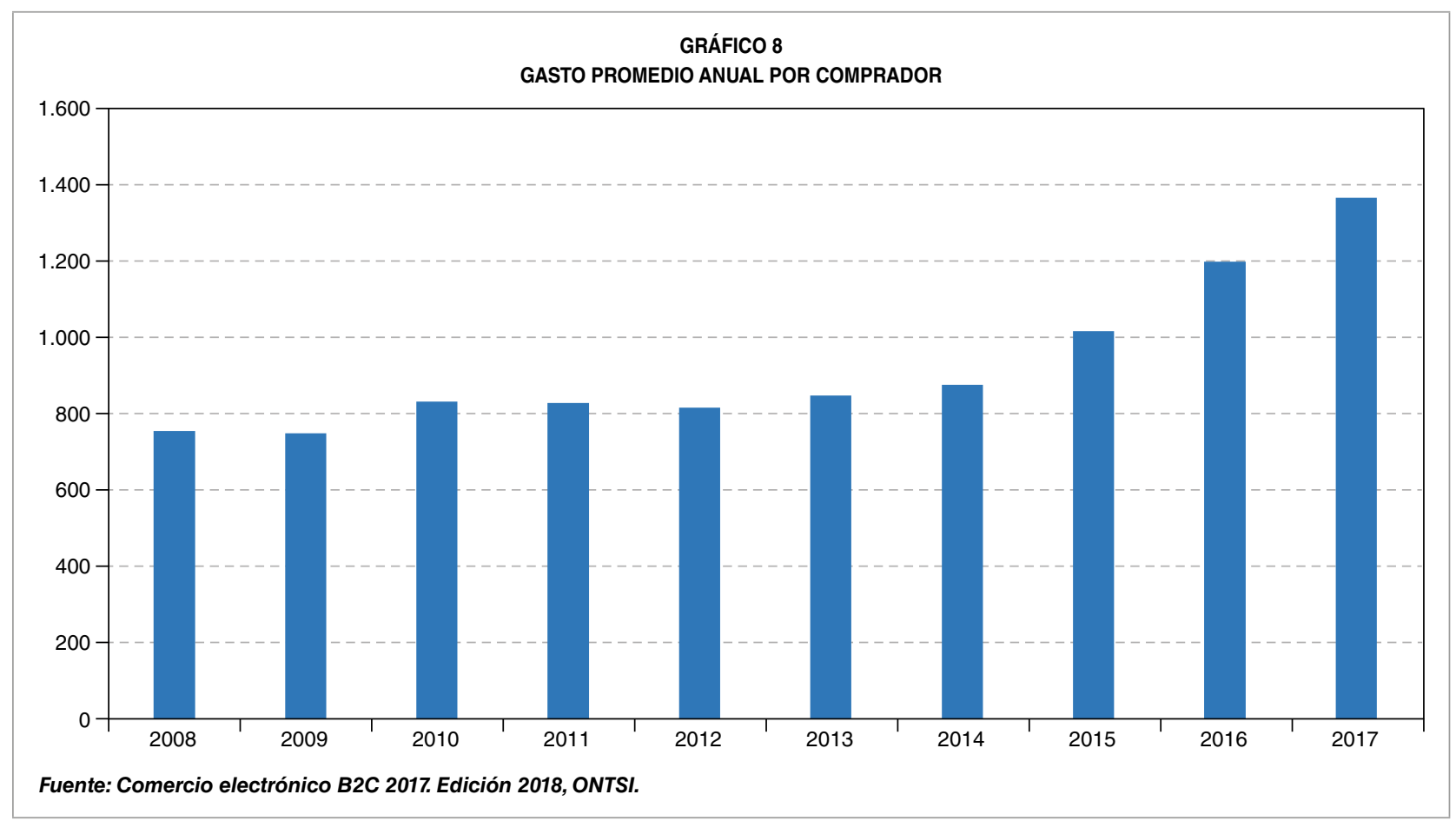

como se desprende de los datos del estudio de $\mathrm{ONTSI}^{8}$ (el gasto medio por comprador online alcanzó los 1.366 euros en 2017).

Existe un amplio margen de crecimiento de esta variable, asociado a la creciente incorporación a las nuevas tecnologías, a la mayor cultura digital y consiguiente generación de confianza, la creciente seguridad en las transacciones, las mejoras en la logística y al propio desarrollo del mercado y diversificación por el lado de la oferta, que empujan al consumidor de forma creciente hacia la digitalización de su patrón de consumo.

Es interesante observar que existe una brecha del uso del comercio online en función de la zona de residencia: un $57 \%$ de los consumidores de zonas urbanas compra en la red, frente a un $45 \%$ de las zonas rurales. Aun así, ambos grupos poblacionales presentan un perfil de crecimiento muy similar.

8 Salvando las diferencias metodológicas, usamos la hipótesis de que el comportamiento de gasto es uniforme independientemente de los sectores considerados.
La conclusión es que el comercio digital minorista en España crece por el lado de la demanda impulsado por la incorporación constante de nuevos consumidores y por el aumento de gasto por consumidor. De ahí que exista un enorme apetito por parte de operadores globales de acceder a nuestro mercado.

\subsection{Mercados y tendencias}

Más allá de los factores competitivos propios de cada operador, el comercio minorista tradicional se ha beneficiado de dos importantes barreras de entrada a sus mercados:

- Renta de situación, es decir, la derivada de su localización, lo cual les proporcionaba un mercado cautivo (los residentes de la zona).

- Información imperfecta acerca de la existencia y disponibilidad de productos sustitutivos y de sus condiciones de precio. 


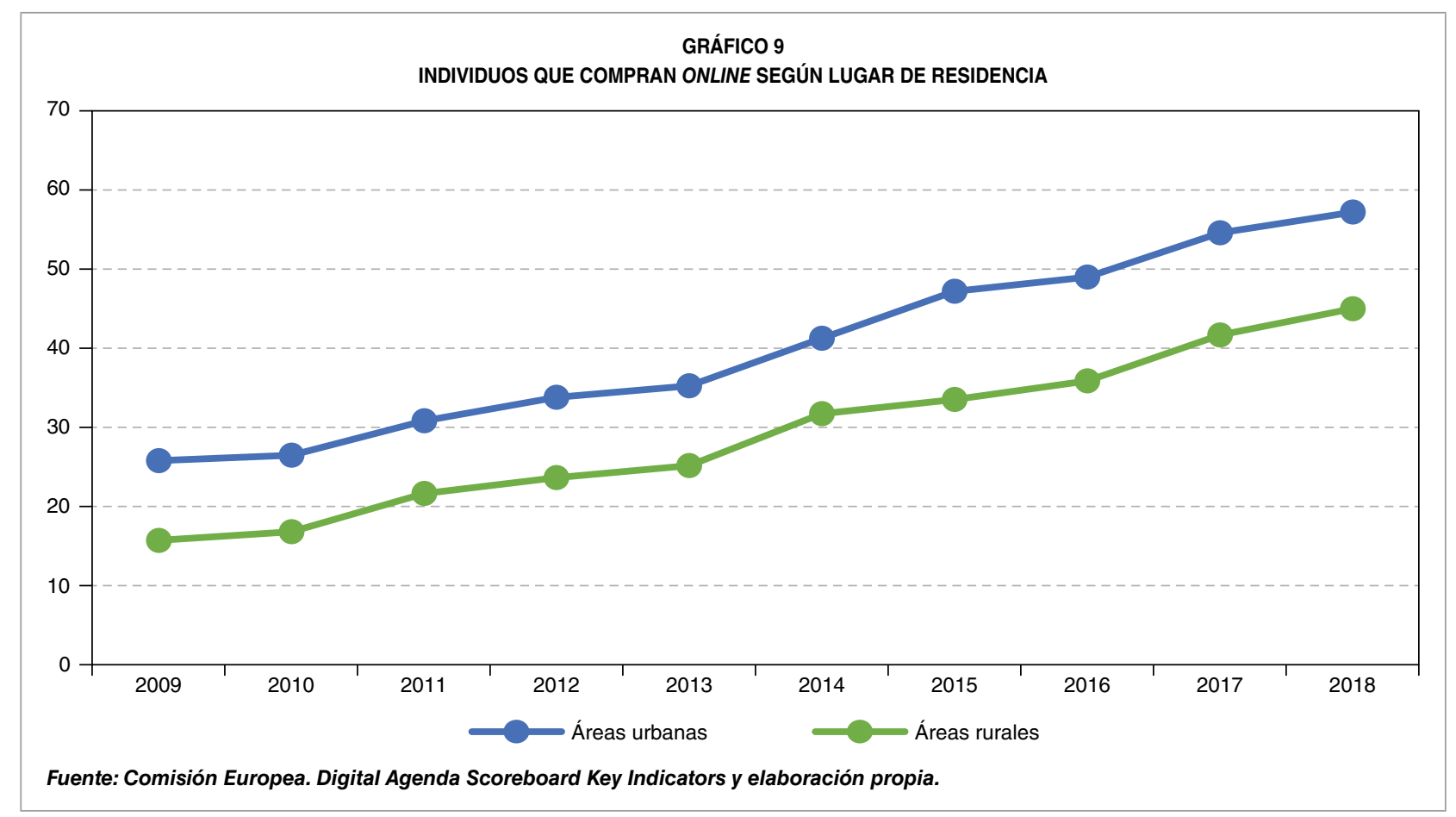

Estos dos factores se han visto progresivamente erosionados a raíz de la generalización del acceso y uso de internet como medio de compra y acceso a la información. Por un lado, ya no es necesario desplazarse para comprar, lo que elimina el carácter presencial del servicio y, por tanto, la relación personal entre comprador y vendedor; y la información es cuasiperfecta, disponible a golpe de click y a coste cero. En estas condiciones, ya no podemos hablar de «comercio interior», porque las fronteras conceptuales han desaparecido: la disponibilidad y el acceso a la oferta comercial de mi barrio son prácticamente equivalentes a la oferta comercial global.

En efecto, el comercio electrónico permite superar ciertos fallos de mercado del comercio tradicional:

- Incrementa sustancialmente el número de oferentes y demandantes, reduciendo el poder de mercado tanto por el lado de la oferta como de la demanda.
- Facilita el acceso a la información relevante (precios, cantidades, condiciones, marcas...), mediante los mecanismos de transparencia y comparabilidad existentes en la red.

- Se reducen los costes de transacción.

- Elimina un gran número de barreras de entrada a los mercados, incluso de otros países.

Sin embargo, hay que valorar el potencial de concentración de poder de mercado y aparición de situaciones anticompetitivas derivadas del crecimiento y enorme poder de mercado de las grandes plataformas globales de comercio online. Esta es, en efecto, una de las tendencias observadas en los últimos años, el creciente predominio de los e-marketplaces o plataformas como canal preferido de compra. El e-marketplace se posiciona en numerosos sectores como canal de compra electrónica favorito, en muchos casos muy por encima de las páginas web de las propias tiendas. 
CUADRO 4

FACTURACIÓN COMERCIO MINORISTA, TOTAL Y ONLINE

\begin{tabular}{|c|c|c|c|c|c|}
\hline \multirow[b]{2}{*}{ Años } & \multicolumn{2}{|c|}{ Facturación comercio minorista } & \multicolumn{2}{|c|}{ Facturación comercio electrónico } & \multirow{2}{*}{$\begin{array}{c}\text { Facturación comercio } \\
\text { electrónico/facturación total (\%) }\end{array}$} \\
\hline & $\begin{array}{l}\text { Millones de } \\
\text { euros }\end{array}$ & $\begin{array}{c}\text { Tasa de variación } \\
\text { (\%) }\end{array}$ & $\begin{array}{l}\text { Millones de } \\
\text { euros }\end{array}$ & $\begin{array}{c}\text { Tasa de variación } \\
\text { (\%) }\end{array}$ & \\
\hline 2008 & 240.651 & - & 1.512 & - & 0,63 \\
\hline 2009 & 219.519 & $-8,78$ & 1.623 & 7,34 & 0,74 \\
\hline 2010 & 221.382 & 0,85 & 1.979 & 21,93 & 0,89 \\
\hline 2011 & 217.287 & $-1,85$ & 2.075 & 4,85 & 0,95 \\
\hline 2012 & 210.487 & $-3,13$ & 3.306 & 59,33 & 1,57 \\
\hline 2013 & 204.932 & $-2,64$ & 2.786 & $-15,73$ & 1,36 \\
\hline 2014 & 204.260 & $-0,33$ & 3.332 & 19,60 & 1,63 \\
\hline 2015 & 213.134 & 4,34 & 4.682 & 40,52 & 2,20 \\
\hline 2016 & 220.119 & 3,28 & 6.551 & 39,92 & 2,98 \\
\hline 2017 & 229.510 & 4,27 & 7.618 & 16,29 & 3,32 \\
\hline
\end{tabular}

Este factor está empujando a las empresas a presentar su oferta por esta vía. Los e-marketplaces se configuran como soluciones llave en mano que incorporan herramientas de posicionamiento online, medios de pago y logística, aunque presentan contrapartidas a tener en cuenta: la competencia en su seno es feroz, más aún cuando en ocasiones se compite con productos de marca blanca (first-party sellers); se desconoce el algoritmo de posicionamiento en el buscador; y se proporcionan datos comerciales valiosos de cuya agregación (big data) la plataforma extrae conclusiones operativas de indudable valor comercial $^{9}$.

En nuestro país, la mitad de las empresas que venden online declaran no tener aún presencia en ningún e-marketplace. Sí se observa una tendencia creciente a la incorporación a este medio de comercialización, habiendo subido el porcentaje de empresas que declaran utilizarlo, desde el $31 \%$ en $2016^{10}$ hasta el $49 \%$ de 2018.

9 La «Regulation on promoting fairness and transparency for business users of online intermediation services» es una propuesta de la Comisión en tramitación que busca reequilibrar derechos y obligaciones entre plataformas online y empresas usuarias.

10 Estudio evolución y perspectivas de e-commerce para 2017 y 2019, Kanlli y D/A Retail.
Más allá de la forma de comercialización online (web propia, de terceros, e-marketplaces...), no cabe duda de que las estrategias empresariales se sofistican para ir más allá del concepto de venta de producto o servicio e incorporar el concepto de experiencia de usuario. El proceso de compra puede iniciarse online y culminarse offline o a la inversa, lo cual determina un modelo de comercio omnicanal donde el éxito e incluso la supervivencia dependen de la capacidad de adaptarse y de satisfacer una demanda compleja y cambiante.

\section{Las cifras del comercio digital español}

De nuevo aquí los datos desmienten el intenso ruido mediático que hace aparecer el sector de comercio minorista como prácticamente dominado por el segmento digital. La facturación online del capítulo $47 \mathrm{CNAE}$ en 2017 se situó en 7.618 millones de euros, cifra que supera ligeramente el $3 \%$ sobre el total.

Las tasas de crecimiento, sin embargo, son propias de un mercado que dista de haber alcanzado su madurez. 


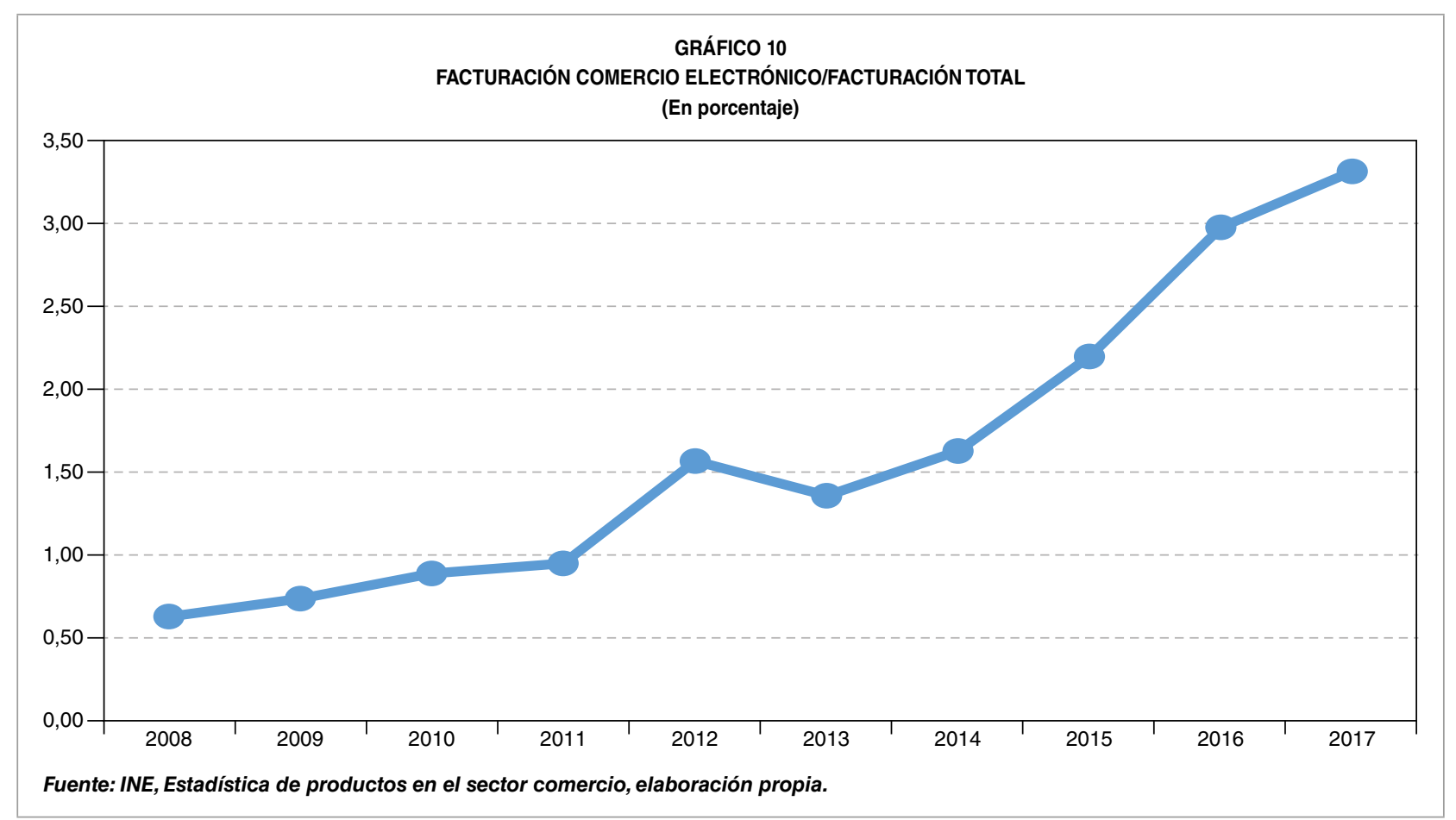

Este dato admite un desglose por tamaño de empresa medido en función del número de empleados. Vemos que el proceso de transformación digital está directamente correlacionado con esta variable. La penetración del canal online como método de comercialización en la empresa española muestra, por tanto, una brecha de dimensión.

Las cifras muy superiores (absolutas y relativas) de negocio online que se manejan $\triangleright$

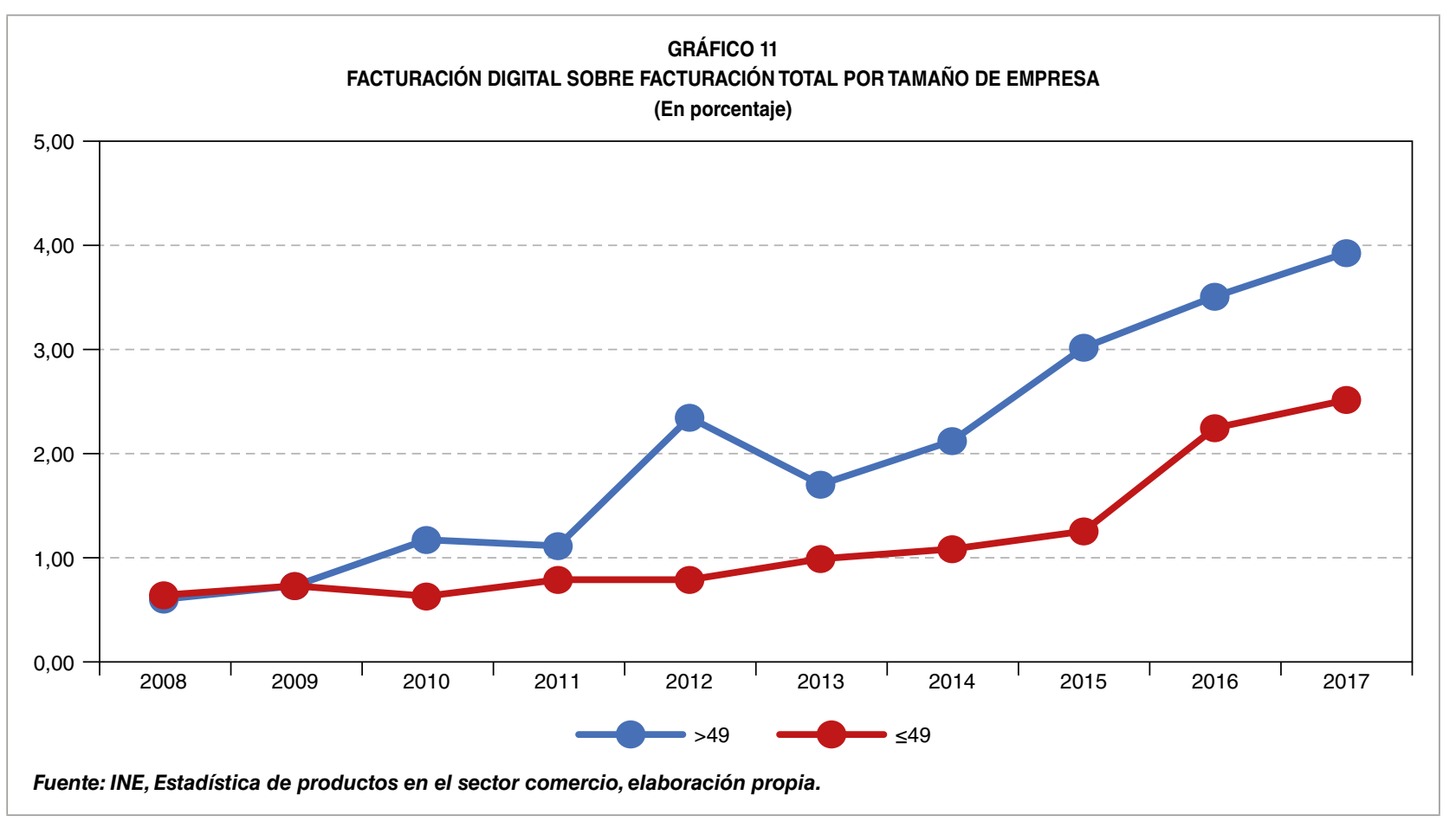


CUADRO 5

DESGLOSE DEL GASTO EN COMERCIO ELECTRÓNICO

(Destacado el gasto en capítulo 47)

\begin{tabular}{|c|c|c|}
\hline Sectores & Gasto total & $\%$ gasto total \\
\hline Ropa, complementos y artículos deportivos & 2.757 & 8,79 \\
\hline Reservas de alojamiento y paquetes turísticos & 7.300 & 23,29 \\
\hline Billetes de transporte & 6.464 & 20,62 \\
\hline Entradas a espectáculos & 1.280 & 4,08 \\
\hline Smartphones y tabletas & 1.350 & 4,31 \\
\hline Alimentación/comida a domicilio & 1.549 & 4,94 \\
\hline Libros, revistas y periódicos & 452 & 1,44 \\
\hline Juguetes, juegos de mesa y juegos en red & 640 & 2,04 \\
\hline Electrónica: imagen, sonido, comunicaciones, hardware & 3.149 & 10,05 \\
\hline Bazar & 539 & 1,72 \\
\hline Electrodomésticos, hogar y jardín & 1.020 & 3,25 \\
\hline Restaurantes & 700 & 2,23 \\
\hline Servicios de internet y telefonía & 590 & 1,88 \\
\hline Servicios personales, experiencias y sensaciones & 365 & 1,16 \\
\hline Ocio al aire libre & 422 & 1,35 \\
\hline Joyería y relojes & 294 & 0,94 \\
\hline Alquiler de coches y motor & 783 & 2,50 \\
\hline Aplicaciones y software & 82 & 0,26 \\
\hline Películas, música y videojuegos para recibirlos en formato físico & 184 & 0,59 \\
\hline Descarga o servicio online de películas, música y videojuegos & 135 & 0,43 \\
\hline Juegos de azar, concursos, apuestas y lotería & 398 & 1,27 \\
\hline Artículos de coleccionismo y antigüedades & 174 & 0,56 \\
\hline Otros & 718 & 2,29 \\
\hline Total & 31.345 & 100,00 \\
\hline
\end{tabular}

habitualmente corresponden a definiciones sectoriales y metodologías diferentes. En concreto, el «Estudio sobre el comercio electrónico B2C 2017» de ONTSI ${ }^{11}$ evalúa en más de 31.000 millones de euros la facturación digital minorista.

Nuestros datos (INE), sin embargo, situarían el valor en 7.600 millones. Podemos sugerir como hipótesis que explicarían el origen de la diferencia (Cuadro 5):

- En principio, tan solo el $41 \%$ del total de los datos de ONTSI (conceptos sombreados)

11 Encuesta a una muestra cercana a 3.000 individuos consumidores representativos de la población española de edad superior a los 15 años. Se trata, por tanto, de datos de demanda. correspondería al capítulo 47, y ni siquiera en su totalidad, ya que algunas líneas recogen componentes excluibles (comida a domicilio, juegos en red...).

- Los datos de ONTSI se obtienen mediante una encuesta a los consumidores, y por tanto recoge tanto las compras procedentes de España como las originarias del exterior, mientras que los datos del INE se refieren a la cifra de negocios de operadores nacionales.

Desde otra perspectiva, podemos analizar el desglose por verticales del sector minorista en función de su facturación de comercio $\triangleright$ 
online declarada: el «retail gran superficie» y los sectores «salud y farmacia» y «tecnología y comunicaciones» son los que mayor proporción de empresas con facturación superior a 5 millones de euros declaran; por contra, en los sectores «alimentación y bebidas», «moda, ropa y complementos» y «libros, revistas y periódicos» predominan el negocio con facturaciones inferiores al millón de euros.

Es decir, y en conclusión, el comercio electrónico minorista es aún una forma de comercio minoritaria en España, pero su progresión es rapidísima. Al apoyarse en la arquitectura de internet, tiene naturaleza global, diluyéndose la tradicional diferenciación entre comercio interior y exterior. La interconexión rápida, sencilla y barata entre oferentes y demandantes permite acceder al mercado global superando las barreras del negocio tradicional.

\section{Internacionalización}

Si la primera gran oleada de la globalización se produjo como consecuencia del crecimiento de las empresas multinacionales, la deslocalización de sus actividades, la apertura de mercados, el abaratamiento del transporte internacional y la mejora de las comunicaciones; la revolución digital es el gran factor desencadenante de la segunda gran oleada.

A partir de la década de los ochenta, y sobre todo de los noventa, las empresas iniciaron su aventura exterior abriendo mercados, buscando oportunidades, estableciendo filiales e invirtiendo en otros países. En nuestros días, el acceso universal a internet, la creciente oferta online, las mejoras en la logística (muy en particular en la última milla) y la confianza en la seguridad de los medios de pago digitales derivan a compradores y vendedores hacia el canal online, bien como fuente de información y comparación, bien como modo de concluir la transacción, bien ambas cosas.

En estas condiciones, una oferta prácticamente global accede a nuestro mercado y compite, casi en pie de igualdad en términos de coste y disponibilidad, con nuestros distribuidores minoristas. Por su parte, el sector exportador tradicional incorpora de manera $\triangle$

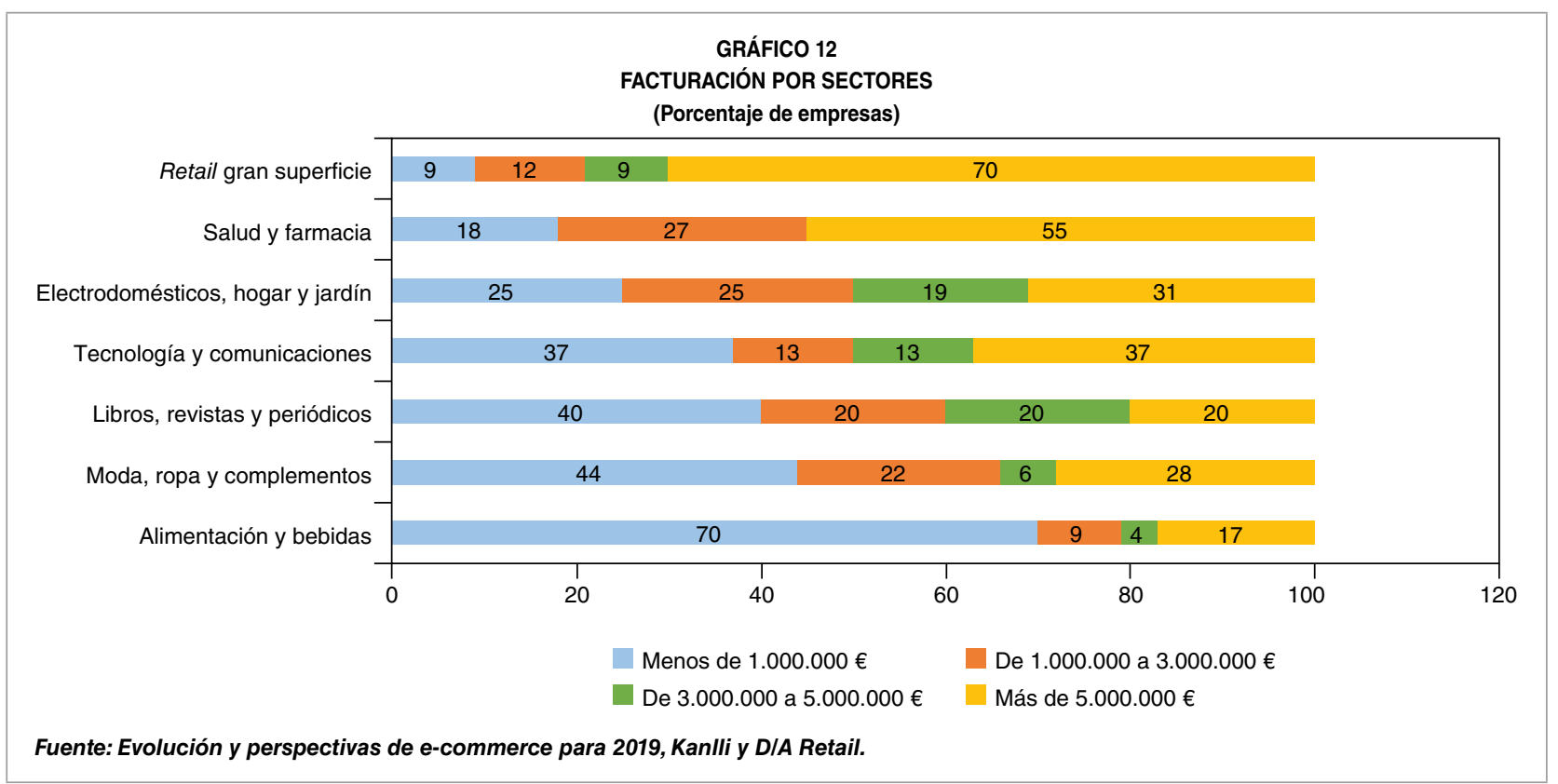




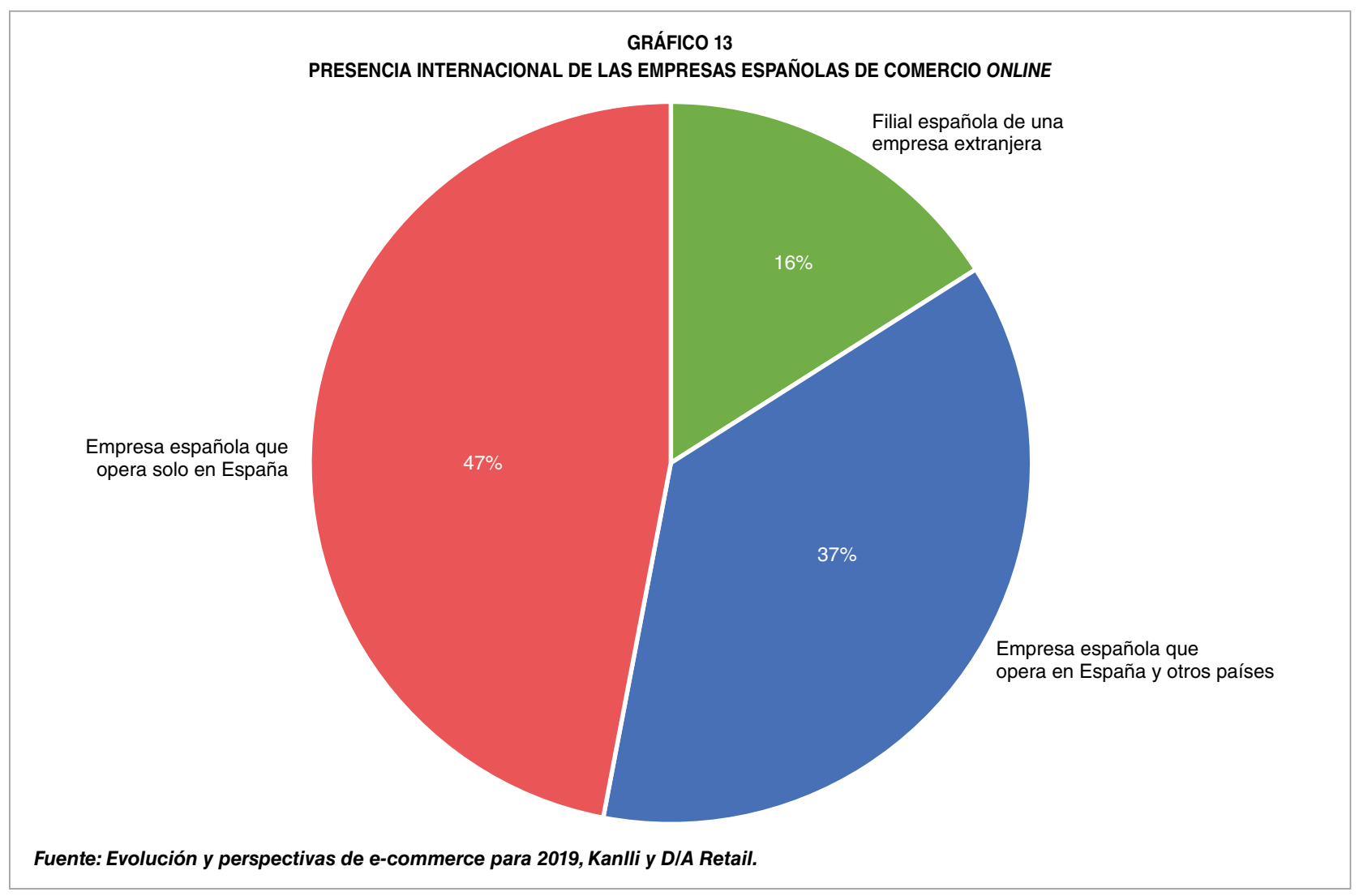

creciente los canales online en su operativa, bien en un contexto $\mathrm{B} 2 \mathrm{C}$, bien a través de plataformas $\mathrm{B}^{2} \mathrm{~B}^{12}$. En el caso español, observamos que solo un $37 \%$ de nuestras empresas opera en los mercados digitales globales.

Si tomamos los datos de la Comisión Nacional de Mercados y Competencia sobre comercio electrónico, y haciendo abstracción de las diferencias metodológicas ${ }^{13}$, podemos extraer conclusiones de la evolución de las variables de exportación e importación online,

\footnotetext{
12 La expresión $\mathrm{B} 2 \mathrm{C}$ se refiere al negocio minorista, «Business to Consumer»; la expresión B2B correspondería al negocio mayorista, «Business to Business».

13 Los datos del INE se obtienen de una encuesta realizada a empresas del sector comercio que ofrece datos desglosados del capítulo 47. Los datos de ONTSI proceden de una encuesta realizada a consumidores. Los datos de CNMC tienen su origen en un censo de todas las transacciones comerciales electrónicas a través de terminales de punto de venta virtuales que tengan España como punto de origen y/o destino y cuyo pago se realiza a través de tarjetas bancarias de pago adscritas a las entidades de pago españolas colaboradoras: SermepaServired, Sistema 4B y Confederación Española de Cajas de Ahorro (CECA-Sistema Euro 6000).
}

así como de la proporción del comercio que corresponde a lo que tradicionalmente se ha llamado «comercio interior» (comercio minorista con origen y destino en nuestro país).

La «tarta» del comercio online en nuestro país ha crecido un $160 \%$ en los últimos cinco años, porcentaje del que el retailer español ha aprovechado un $120 \%$ (incremento del comercio «interior»y de las exportaciones). Mientras tanto, las importaciones online han crecido un $185 \%$, con lo que pasan de absorber el $41,7 \%$ de las ventas online al $48,3 \%$. Este dato es muy relevante por cuanto pone de manifiesto el elemento de presión competitiva que en nuestro mercado doméstico ejercen de manera creciente los operadores foráneos a través del circuito online e incide en la necesidad de seguir realizando esfuerzos en el acceso a mercados exteriores.

El reto, por tanto, para el sector retail es doble: competir internamente con productos y $\triangleright$ 


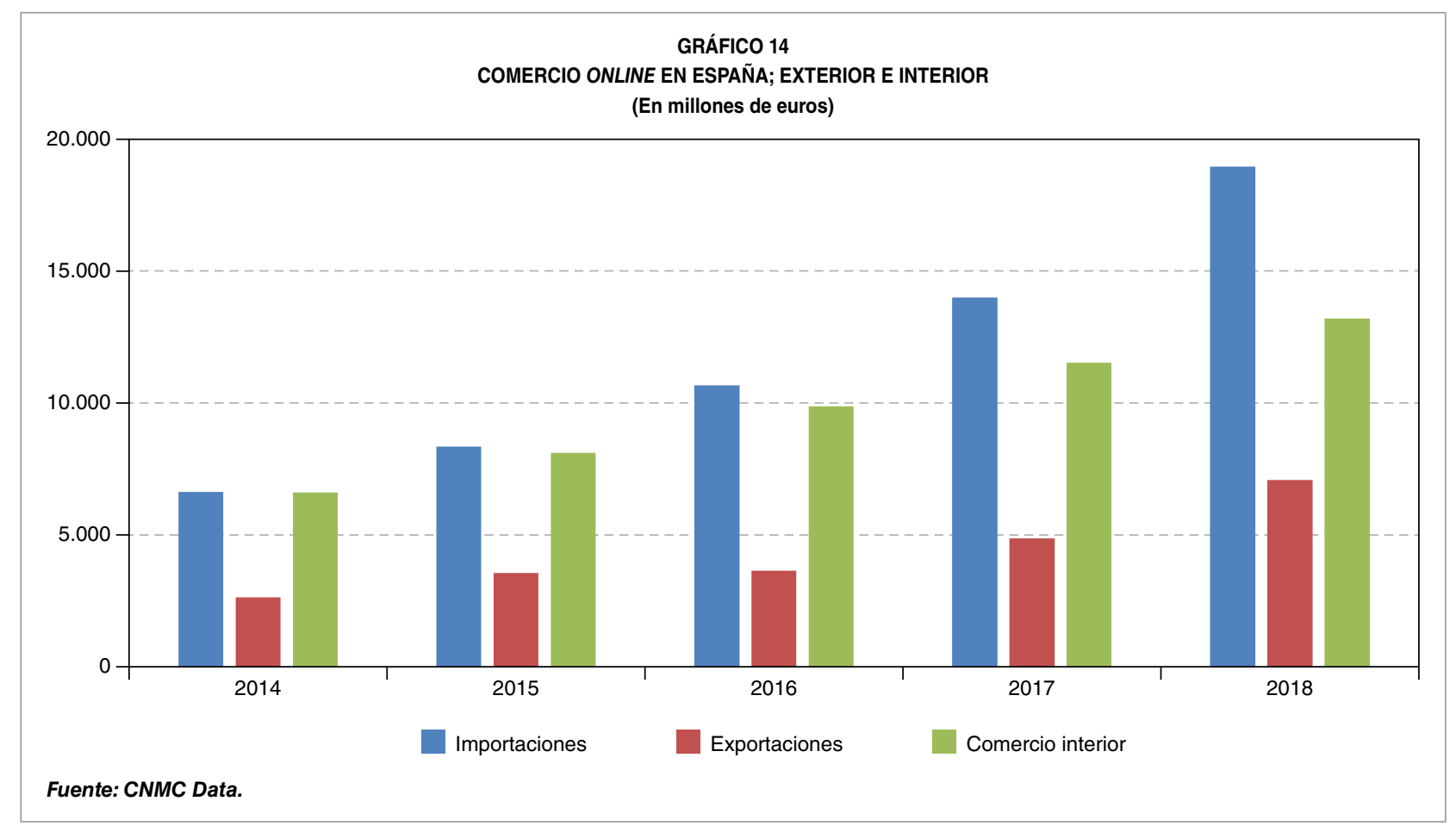

servicios extranjeros, cada vez más presentes y fácilmente disponibles; y su propia internacionalización, es decir, el acceso a mercados exteriores en cuanto prestadores del servicio de distribución comercial, sector en el que operan a escala global las grandes plataformas (Amazon, Aliexpress, eBay...). Aunque los líderes del sector proceden mayoritariamente de Estados Unidos y China, existen algunos casos de éxito en Europa (Asos, Zalando). En España, la actividad online de los grandes de la distribución comercial se desarrolla aún a escala nacional, por lo que se puede concluir que el reto de la internacionalización del sector de distribución minorista español está pendiente.

\section{Conclusiones}

De cara a la consecución del objetivo de impulsar el desarrollo del comercio electrónico en España, se identifican tres retos principales:
- Escuchar al usuario: a tal fin se ha creado el Observatorio de Comercio 4.0, dependiente de la Secretaría de Estado de Comercio, cuyo fin es canalizar un diálogo que permita identificar las necesidades y el posicionamiento del sector de cara al desarrollo de una acción de gobierno centrada en las necesidades del usuario (user-centric) como forma de validar las actuaciones de política sectorial. En él, instituciones públicas, departamentos de la Administración en sus distintos niveles, asociaciones sectoriales y expertos analizan y debaten los problemas del comercio minorista en un entorno omnicanal, y proponen líneas de actuación.

- Facilitar la transformación digital: la empresa minorista, muy en particular las microempresas y las pymes, precisan de acciones de estímulo y acompañamiento a la digitalización, mediante actuaciones de ámbito público-privado que $\triangleright$ 
incluyan iniciativas de formación, información y apoyo financiero, como vía de apoyo a la digitalización de nuestro tejido empresarial y fomentar su competitividad. En este sentido, la Secretaría de Estado de Comercio mantiene un convenio de colaboración de carácter anual con la Cámara de España dotado con 6 millones de euros, cuyo fin es desarrollar acciones concretas de modernización y acompañamiento a la digitalización del sector retail. Por otra parte, la Secretaría de Estado va a lanzar la plataforma profesional ComercioConectado.com, cuyo objetivo es aunar las acciones de apoyo al sector, generar conocimiento relevante para los operadores, identificar tendencias de éxito a nivel global y poner en contacto al sector con los proveedores de soluciones.

- Adecuar el ordenamiento jurídico español a la economía digital: es preciso coordinar las actuaciones legislativas con base en los principios de regulación eficiente, identificando tres posibles actuaciones:

- Desregular: cuando la normativa actual represente un obstáculo, salvaguardando los objetivos legítimos de política general y analizando los efectos sobre los sectores de la economía tradicional.

- Regular: la economía digital puede dar lugar a la aparición de situaciones nuevas que precisen tratamiento específico, bien por parte del Gobierno (top down) o mediante procesos de autorregulación sectorial (bottom up).

- Mantener y aplicar: por defecto, la economía digital se encuentra sometida al marco legislativo en vigor. Sin embargo, su propia naturaleza dificulta, y en ocasiones imposibilita, la aplicación de la legislación (fraudes en las declaraciones aduaneras, incumplimiento de la normativa de propiedad intelectual, desprotección del consumidor, incapacidad de hacer cumplir la normativa en determinados sectores regulados, como el farmacéutico, problemas relacionados con los impuestos a operadores no establecidos...). Corresponde al Estado diseñar mecanismos que hagan efectivo el cumplimiento, o adaptar los procedimientos a la nueva realidad.

El mercado va siempre por delante de la Administración, más aún en sectores como los que nos ocupa, caracterizados por un enorme dinamismo, lo cual requiere una actuación de inteligencia prospectiva que, sin interferir en su desarrollo, permita detectar sus necesidades, apoyar su desarrollo y prevenir y corregir posibles distorsiones e ineficiencias para mantener el equilibrio entre operadores (level playing field). Para ello los poderes públicos han de anticiparse y diseñar el marco de acompañamiento al desarrollo de la actividad económica, que no puede distinguir entre digital o no, porque ya no hay dos economías, online y offline, sino tan solo una, conectada y global. 


\begin{abstract}
ANEXO 1
Capítulo 47 CNAE: Comercio al por menor, excepto de vehículos de motor y motocicletas

471 Comercio al por menor en establecimientos no especializados.

472 Comercio al por menor de productos alimenticios, bebidas y tabaco en establecimientos especializados.

473 Comercio al por menor de combustible para la automoción en establecimientos especializados.

474 Comercio al por menor de equipos para las tecnologías de la información y las comunicaciones en establecimientos especializados.

475 Comercio al por menor de otros artículos de uso doméstico en establecimientos especializados.

476 Comercio al por menor de artículos culturales y recreativos en establecimientos especializados.

477 Comercio al por menor de otros artículos en establecimientos especializados.

478 Comercio al por menor en puestos de venta y en mercadillos.

479 Comercio al por menor no realizado ni en establecimientos ni en puestos de venta ni en mercadillos.

El capítulo 47 excluye expresamente varios conceptos:

- La venta de vehículos de motor y motocicletas (capítulo 45 del CNAE) que, por sus características y operativa diferenciales, así como por su importancia y volumen, merece capítulo aparte. En 2017 (último dato disponible), este concepto alcanzó un valor equivalente al $36 \%$ del total del capítulo 47 en su conjunto, por lo que es fácil concluir que su consideración conjunta distorsionaría en gran medida el análisis del comercio minorista.

- Las actividades de distribución mayorista, que en comercio electrónico se suelen denominar "comercio B2B» (business to business), frente al «comercio B2C» (business to consumer), que sería el comercio minorista. Corresponden al capítulo 46 del CNAE.

- La venta de servicios distintos de los servicios de distribución comercial. Dentro del sector servicios, el CNAE incluye grupos específicos para actividades como el suministro de energía y agua, construcción, transporte, hostelería, información y comunicaciones y financieros. Algunos de estos conceptos se suelen incluir de forma habitual en el análisis de, por ejemplo, facturación anual de comercio electrónico minorista, sin embargo nosotros no los vamos a considerar a efectos de consistencia.
\end{abstract}

